\title{
Kidney dysfunction following adrenalectomy in autosomal dominant polycystic kidney disease complicated with primary aldosteronism: A case report
}

\author{
HIROYUKI HIRAI $^{1,2}$, MAKOTO KANNO ${ }^{1}$, TSUYOSHI WATANABE ${ }^{1,3}$ and HIROAKI SATOH ${ }^{1,4}$ \\ ${ }^{1}$ Department of Nephrology, Hypertension, Diabetology, Endocrinology and Metabolism, Fukushima Medical University, \\ Fukushima, Fukushima 960-1295; ${ }^{2}$ Department of Internal Medicine, Shirakawa Kosei General Hospital, Shirakawa, \\ Fukushima 961-0005; ${ }^{3}$ Department of Internal Medicine, Fukushima Rosai Hospital, Iwaki, Fukushima 973-8403; \\ ${ }^{4}$ Department of Metabolism and Endocrinology, Juntendo University School of Medicine, Bunkyo, Tokyo 113-8421, Japan
}

Received January 31, 2017; Accepted April 21, 2017

DOI: 10.3892/etm.2017.4588

\begin{abstract}
The present study reported a case of autosomal dominant polycystic kidney disease complicated with primary aldosteronism in a 49-year-old woman. The patient was referred for refractory hypertension. Laboratory examinations revealed low potassium and renin levels. Computed tomography indicated a right adrenal tumor and multiple renal cysts. Adrenal vein sampling revealed a high aldosterone level on the side of the tumor. The patient was diagnosed with autosomal dominant polycystic kidney disease complicated by primary aldosteronism and adrenalectomy was performed. Over the following 7 months, the estimated glomerular filtration rate decreased from 76 to $48 \mathrm{ml} / \mathrm{min} / 1.73 \mathrm{~m}^{2}$, which was attributed to glomerular hyperfiltration correction induced by hyperaldosteronism remission, indicating kidney dysfunction. Clinicians must therefore monitor for the unmasking of kidney dysfunction following adrenalectomy in such cases.
\end{abstract}

\section{Introduction}

Autosomal dominant polycystic kidney disease (ADPKD) is a hereditary kidney disease with a poor renal outcome. Pathogenesis involves cyst formation and growth, which leads to an increase in kidney volume and a decline in glomerular filtration rate (1). Approximately $50 \%$ of ADPKD patients

Correspondence to: Dr Hiroaki Satoh, Department of Metabolism and Endocrinology, Juntendo University School of Medicine, 2-1-1 Hongo, Bunkyo, Tokyo 113-8421, Japan

E-mail: hk-sato@juntendo.ac.jp

Abbreviations: ADPKD, autosomal dominant polycystic kidney disease; PA, primary aldosteronism; eGFR, estimated glomerular filtration rate

Key words: autosomal dominant polycystic kidney disease, kidney dysfunction, primary aldosteronism, adrenalectomy finally need renal replacement therapy (1). In addition, ADPKD is sometimes complicated with hypertension (1).

Epidemiologically, recent prevalence of ADPKD in Japan remains unclear. However, Higashihara et al (2) reported a prevalence of ADPKD of 117 in 1,000,000 in Japan at the end of 1994. In Western countries, ADPKD affects both sexes and all ethnicities, with an estimated frequency of between 1 in 400 to 1 in 1,000 live births (1).

Primary aldosteronism (PA) is an endocrine disease that causes secondary hypertension and increases the risk of cardiovascular disease. Among cases of hypertension, Utsumi et al (3) reported that 6-11\% are secondary to PA, although prevalence varies worldwide. The pathogenesis of PA is excess secretion of aldosterone from bilateral or unilateral adrenal gland or tumors (3). The early discovery and treatment of PA is a crucial clinical issue to prevent progression of atherosclerosis. The classical symptoms of PA are refractory hypertension and hypokalemia. However, those symptoms do not always occur, which makes early discovery difficult (3). Adrenalectomy is widely performed to treat adrenal tumors; however, there is increasing focus on attenuating the progression of renal dysfunction following adrenalectomy to treat PA (3-5), the mechanism of which has not been fully elucidated.

The primary aims of treating ADPKD and PA are controlling hypertension and preserving kidney function. However, only a few cases of the two diseases occurring together have been reported $(6,7)$. These reports have focused on diagnosing these disorders, however to the best of our knowledge, the effect of adrenalectomy on renal function in patients with ADPKD and PA has not been fully elucidated.

The present report documents the case of a patient with ADPKD who experienced a decline in estimated glomerular filtration rate (eGFR) following adrenalectomy to treat PA.

\section{Case report}

In July 2010, a 49-year-old woman was referred to the Department of Nephrology, Hypertension, Diabetology, Endocrinology, and Metabolism, Fukushima Medical University Hospital (Fukushima, Japan) for evaluation of 
poorly controlled hypertension. The patient had a 9-year history of hypertension. Hypertension was defined as systolic blood pressure $>140 \mathrm{mmHg}$ or diastolic blood pressure $>90 \mathrm{mmHg}$ in a sitting position. In the preceding 3 years, the patient had undergone treatment with nifedipine $(40 \mathrm{mg} /$ day $)$, imidapril ( $5 \mathrm{mg} / \mathrm{day})$, and bisoprolol $(5 \mathrm{mg} / \mathrm{day})$. The patient's resting blood pressure at home had been $120-140 / 70-80 \mathrm{mmHg}$ (normal range: Systolic blood pressure $<135 \mathrm{mmHg}$ and diastolic blood pressure $<85 \mathrm{mmHg}$ ). The patient's measured period of blood pressure was $\sim 3$ years.

However, 2 months before referral, the patient's blood pressure increased to $160-170 / 80-90 \mathrm{mmHg}$. Upon admittance, the patient underwent a physical examination that revealed a height of $156.5 \mathrm{~cm}$; a weight of $71.2 \mathrm{~kg}$; a body mass index of $29.1 \mathrm{~kg} / \mathrm{m}^{2}$; a temperature of $36.4^{\circ} \mathrm{C}$; a resting blood pressure of $157 / 83 \mathrm{mmHg}$ and a regular pulse of 50 beats/min. Fundus examination revealed hypertensive changes (H3S2 in the left eye and H2S2 in the right eye by Scheie's classification) (8). Therefore, the patient had at least moderate hypertensive and atherogenic fundus changes. The patient's family history was significant, due to the patient's mother having polycystic kidney disease. Laboratory examinations revealed hypokalemia and anemia due to iron deficiency (Table I).

Plasma renin activity (PRA) was $\leq 0.1 \mathrm{ng} / \mathrm{ml} / \mathrm{h}$ (normal range, $0.1-0.3 \mathrm{ng} / \mathrm{ml} / \mathrm{h}$ ), thus bisoprolol was discontinued to exclude a false low result. Oral iron supplements (100 mg/day) were administered, resulting in gradual improvement of anemia. Thereafter, a captopril $(50 \mathrm{mg})$ stimulation test was conducted producing a low renin response (Table II; normal range, renin response $>1.0 \mathrm{ng} / \mathrm{ml} / \mathrm{h}$, aldosterone-to-renin ratio (ARR) of 60 or 90 min $<200$ ). Abdominal computed tomography and magnetic resonance imaging revealed a right adrenal tumor $\sim 1.0 \mathrm{~cm}$ in size and multiple cysts in the liver and kidneys (Fig. 1). The estimated volume of the bilateral kidneys was calculated using the volumetric method and the following formula: Volume $=\pi / 6 \mathrm{x}$ length $\mathrm{x}$ width $\mathrm{x}$ depth $(9,10)$ and was determined to be $\sim 705.4 \mathrm{ml}$.

To evaluate the adrenal tumor further, adrenal vein sampling was conducted. A catheter was inserted into the bilateral adrenal vein via the femoral vein. Blood samples were collected from the inferior vena cava, left adrenal vein and right adrenal vein. A $0.25 \mathrm{mg}$ dose of tetracosactide acetate (adrenocorticotripic hormone; Daiichi Sankyo Co., Ltd., Tokyo, Japan) was administered intravenously, and after $30 \mathrm{~min}$, blood samples were collected from the same locations again. The serum aldosterone level was high on the side of the tumor (Table III). The patient's results fulfilled the diagnostic criteria for ADPKD (11) and PA $(12,13)$.

Eplerenone (selective aldosterone antagonist; Pfizer Japan, Inc., Tokyo, Japan) was administered, beginning at $50 \mathrm{mg} /$ day (once after breakfast) for 15 days, thereafter, $75 \mathrm{mg} /$ day (once after breakfast) for 30 days and finally increasing to $100 \mathrm{mg} /$ day (50 mg twice a day, after breakfast and dinner) for $\sim 15$ weeks, until adrenalectomy. This resulted in a reduction of blood pressure to $130 / 80 \mathrm{mmHg}$, which was within normal blood pressure range of $<135 / 85 \mathrm{mmHg}$. In April 2011, right adrenalectomy was successfully performed. Hemodynamic disturbances during the surgery or in the immediate post-surgical course were not evident. Weiss criteria $(14,15)$ were used to distinguish between adrenal adenoma or malignant tumor. For
Table I. Laboratory data on first visit.

\begin{tabular}{|c|c|c|}
\hline Parameter & Result & Normal range \\
\hline $\mathrm{WBC}($ cells $/ \mu \mathrm{l})$ & 6,000 & $2,800-8,800$ \\
\hline $\mathrm{RBC}\left(\right.$ cells $\left.\times 10^{4} / \mu \mathrm{l}\right)$ & 389 & $366-478$ \\
\hline $\mathrm{Hb}(\mathrm{g} / \mathrm{dl})$ & 6.9 & $11.6-14.0$ \\
\hline $\operatorname{Hct}(\%)$ & 25.1 & $34.1-41.7$ \\
\hline Plt (Plt x10 $4 / \mu 1)$ & 26.3 & $14.7-34.1$ \\
\hline $\operatorname{MCV}(\mathrm{fl})$ & 64.5 & $81.8-97.2$ \\
\hline $\mathrm{MCH}(\%)$ & 17.7 & $27.1-33.5$ \\
\hline $\mathrm{TP}(\mathrm{g} / \mathrm{dl})$ & 7.2 & $6.7-8.3$ \\
\hline $\mathrm{Alb}(\mathrm{g} / \mathrm{dl})$ & 4.1 & $3.9-4.9$ \\
\hline AST (IU/l) & 14 & $13-33$ \\
\hline ALT (IU/l) & 10 & $6-27$ \\
\hline$\gamma \mathrm{GT}(\mathrm{IU} / \mathrm{l})$ & 17 & $10-47$ \\
\hline T-Bil (mg/dl) & 1.0 & $0.2-1.2$ \\
\hline CRP (mg/dl) & 0.67 & $0-0.3$ \\
\hline $\mathrm{Fe}(\mu \mathrm{g} / \mathrm{dl})$ & 13 & $43-172$ \\
\hline UIBC $(\mu \mathrm{g} / \mathrm{dl})$ & 336 & $137-325$ \\
\hline Ferritin (ng/ml) & 8 & $12-60$ \\
\hline $\mathrm{FPG}(\mathrm{mg} / \mathrm{dl})$ & 98 & $70-109$ \\
\hline $\mathrm{Na}(\mathrm{mEq} / \mathrm{l})$ & 143 & $138-146$ \\
\hline $\mathrm{K}(\mathrm{mEq} / \mathrm{l})$ & 2.4 & $3.6-4.9$ \\
\hline $\mathrm{Cl}(\mathrm{mEq} / \mathrm{l})$ & 98 & 99-109 \\
\hline BUN (mg/dl) & 7 & $8-22$ \\
\hline $\mathrm{Cre}(\mathrm{mg} / \mathrm{dl})$ & 0.51 & $0.4-0.7$ \\
\hline $\mathrm{eGFR}\left(\mathrm{ml} / \mathrm{min} / 1.73 \mathrm{~m}^{2}\right)$ & 143 & $\geq 60$ \\
\hline $\mathrm{UA}(\mathrm{mg} / \mathrm{dl})$ & 6.1 & $2.3-7.0$ \\
\hline U-Glucose & $(-)$ & $(-)$ \\
\hline U-Protein & $(1+)$ & $(-)$ \\
\hline U-Blood & $(-)$ & $(-)$ \\
\hline U-Na (mEq/l) & 9 & $40-90$ \\
\hline U-K (mEq/l) & 24 & $20-60$ \\
\hline $\mathrm{U}-\mathrm{Cl}(\mathrm{mEq} / \mathrm{l})$ & 227 & $40-120$ \\
\hline U-Cre (mg/dl) & 98 & 70-109 \\
\hline PRA (ng/ml/h) & $\leq 0.1$ & $0.1-0.3$ \\
\hline Aldosterone $(\mathrm{pg} / \mathrm{ml})$ & 149 & 29.9-159 \\
\hline
\end{tabular}

WBC, white blood cells; RBC, red blood cells; Hb, hemoglobin; Hct, hematocrit; Plt, platelets; $\mathrm{MCV}$, mean corpuscular volume; $\mathrm{MCH}$, mean corpuscular hemoglobin; TP, total protein; Alb, albumin; AST, aspartate aminotransferase; ALT, alanine aminotransferase; $\gamma$-GTP, $\gamma$-glutamyl transpeptidase; T-Bil, total bilirubin; CRP, C-reactive protein; UIBC, unsaturated iron binding capacity; FPG, fasting plasma glucose; BUN, blood urea nitrogen; Na, sodium; K, potassium; $\mathrm{Cl}$, chloride; Cre, creatinine; eGFR, estimated glemerular filtration rate, calculated as $194 \mathrm{xCr}-1.094 x a g e-0.287 \mathrm{x} 0.739$; UA, uric acid; PRA, plasma renin activity.

pathological evaluation, the specimen was fixed with $10 \%$ formalin fixation for 3 days at room temperature. The thickness of sections was approximately $5 \mu \mathrm{m}$. The paraffin embedded tissue sections were de-paraffinized by xylene, and then stained with hematoxylin-eosin. Sections were examined under an Olympus BX51 microscope at magnification x200. 
Table II. Captopril stimulation test.

Time $(\min )$

\begin{tabular}{lcccc}
\cline { 2 - 3 } Parameter & 0 & 60 & 90 & Normal range \\
\hline Renin $(\mathrm{ng} / \mathrm{ml} / \mathrm{h})$ & 0.3 & 0.3 & 0.3 & $0.1-0.3$ \\
Aldosterone $(\mathrm{pg} / \mathrm{ml})$ & 129 & 194 & 228 & $29.9-159$ \\
Aldosterone/renin ratio & 430 & 646.7 & 760 & $\leq 200$ \\
\hline
\end{tabular}

Pathologically, there were no evidence of necrosis, mitosis or atypical mitosis. From the above pathological findings, the tumor was diagnosed as adenoma.

Postoperatively, potassium levels normalized. However, kidney function worsened following adrenalectomy, despite good control of her hypertension. Fig. 2 summarizes the clinical course of the patient over $\sim 5$ years. The eGFR (calculated as $194 \mathrm{x}$ creatinine $\mathrm{e}^{-1.094} \mathrm{x}$ age $\mathrm{ag}^{-0.287} \mathrm{x} 0.739$ ) (16) decreased by $36.8 \%$ over the 7 months immediately following adrenalectomy, from 76 to $48 \mathrm{ml} / \mathrm{min} / 1.73 \mathrm{~m}^{2}$ (normal range, $>90 \mathrm{ml} / \mathrm{min} / 1.73 \mathrm{~m}^{2}$ ). The serum creatinine level increased from 0.64 to $0.97 \mathrm{mg} / \mathrm{dl}$. Home blood pressure measurements during this time remained 110-120/60-80 mmHg.

After the initial decline in eGFR over the 7 months following adrenalectomy, it stabilized to some extent, with a much slower rate of decline (Fig. 2), suggesting that this was the natural level of the patient's renal function due to ADPKD. Follow-up abdominal computed tomography $\sim 9$ months after surgery indicated no marked changes in the renal cysts. The estimated bilateral kidney volume was $\sim 707.7 \mathrm{ml}$; virtually unchanged from the first examination. The patient continued to take $4 \mathrm{mg} /$ day candesartan (angiotensin II receptor antagonist; Takeda Pharmaceutical Co., Ltd., Osaka, Japan), once after breakfast, which effectively controlled blood pressure.

\section{Discussion}

The present report highlights three important issues. Firstly, PA may co-exist with ADPKD. Secondly, as in this case, PA might mask ADPKD kidney dysfunction, which only manifests following adrenalectomy. Therefore, clinicians should remain vigilant for the unmasking of kidney dysfunction following adrenalectomy in patients with ADPKD. Finally, following adrenalectomy, it appears that renal function may decrease to levels expected over the natural clinical course of ADPKD.

ADPKD is attributed to mutations in the PKD1 or PKD2 genes (17) that produce the polycystin-1 and polycystin-2 proteins, respectively. Loss of function of either protein ultimately results in the formation of cysts in the kidney. Growth and expansion of cysts is a critical factor in progressive ADPKD. In individuals harboring a mutation, cysts are almost always detectable by early adulthood (18). The cysts are thought to induce focal areas of renal ischemia and enhanced renin release, increasing renin-aldosterone system activity, with the result that extracellular volume expansion is often present in the early stages of ADPKD (19). It is not unusual for young adults with ADPKD to exhibit hypertension before they experience evident renal dysfunction $(20,21)$. The mechanism
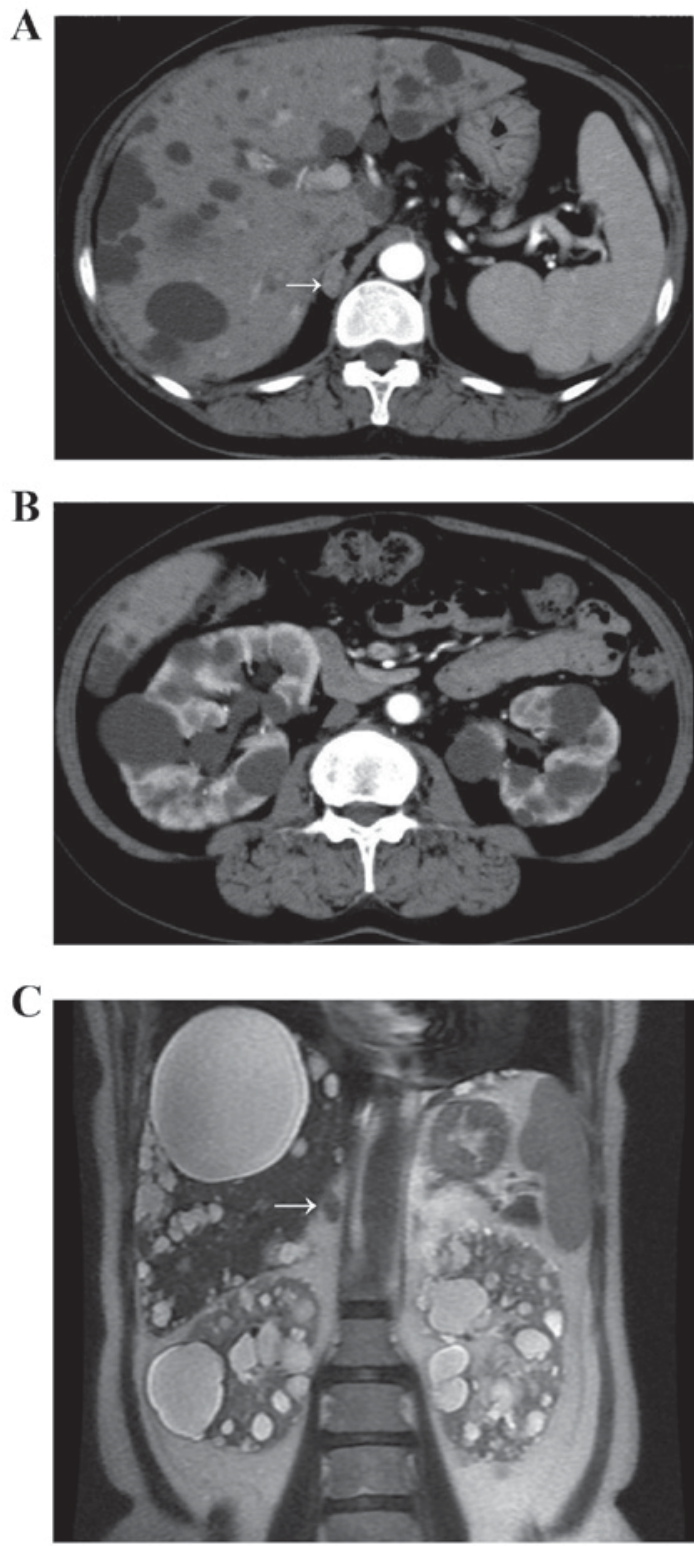

Figure 1. Abdominal computed tomography and magnetic resonance imaging. Abdominal computed tomography indicated (A) a right adrenal (arrow) tumor $\sim 1.0 \mathrm{~cm}$ in size and multiple cysts in the liver and (B) the kidneys. (C) Abdominal T2-weighted coronal magnetic resonance image identified a right adrenal (arrow) tumor $\sim 1.0 \mathrm{~cm}$ in size and multiple cysts in the liver and the bilateral kidneys.

of hypertension in ADPKD is thought to be complex. A number of potential factors have been proposed, including the renin-aldosterone system, endothelial dysfunction, increased sympathetic activity, increased endothelin-1 levels and arterial stiffness (22).

However, the role of the renin-aldosterone system in ADPKD is considered to be particularly important (1). One of the reasons is that hyperaldosteronism may not only to increase cardiovascular risk and secondary hypertension but may also to contribute to the growth of cysts, with hypokalemia implicated as a direct growth factor for cysts (22). Therefore, the early diagnosis and correction of underlying PA is critical in patients with ADPKD. However, as ADPKD is often complicated by hypertension in the early stages, the coexistence of PA may not be considered. In this regard, 
Table III. Adrenal vein sampling.

\begin{tabular}{lccc}
\hline Vein & Aldosterone $(\mathrm{pg} / \mathrm{ml})$ & Cortisol $(\mu \mathrm{g} / \mathrm{dl})$ & Aldosterone/cortisol \\
\hline Inferior vena cava & 66.1 & 4.0 & 16.5 \\
Left adrenal vein & 88.3 & 13.9 & 6.4 \\
Right adrenal vein & 2,010 & 15.5 & 129.7 \\
Inferior vena cava $^{\mathrm{a}}$ & 260 & 15 & 17.3 \\
Left adrenal vein $^{\mathrm{a}}$ & 2,100 & 630 & 3.3 \\
Right adrenal vein $^{\mathrm{a}}$ & 67,300 & 1,100 & 61.2
\end{tabular}

${ }^{\mathrm{a} F o l l o w i n g ~ i n j e c t i o n ~ o f ~ t e t r a c o s a c t i d e ~ a c e t a t e ~(A C T H ~ 1-24, ~} 0.25 \mathrm{mg}$ )

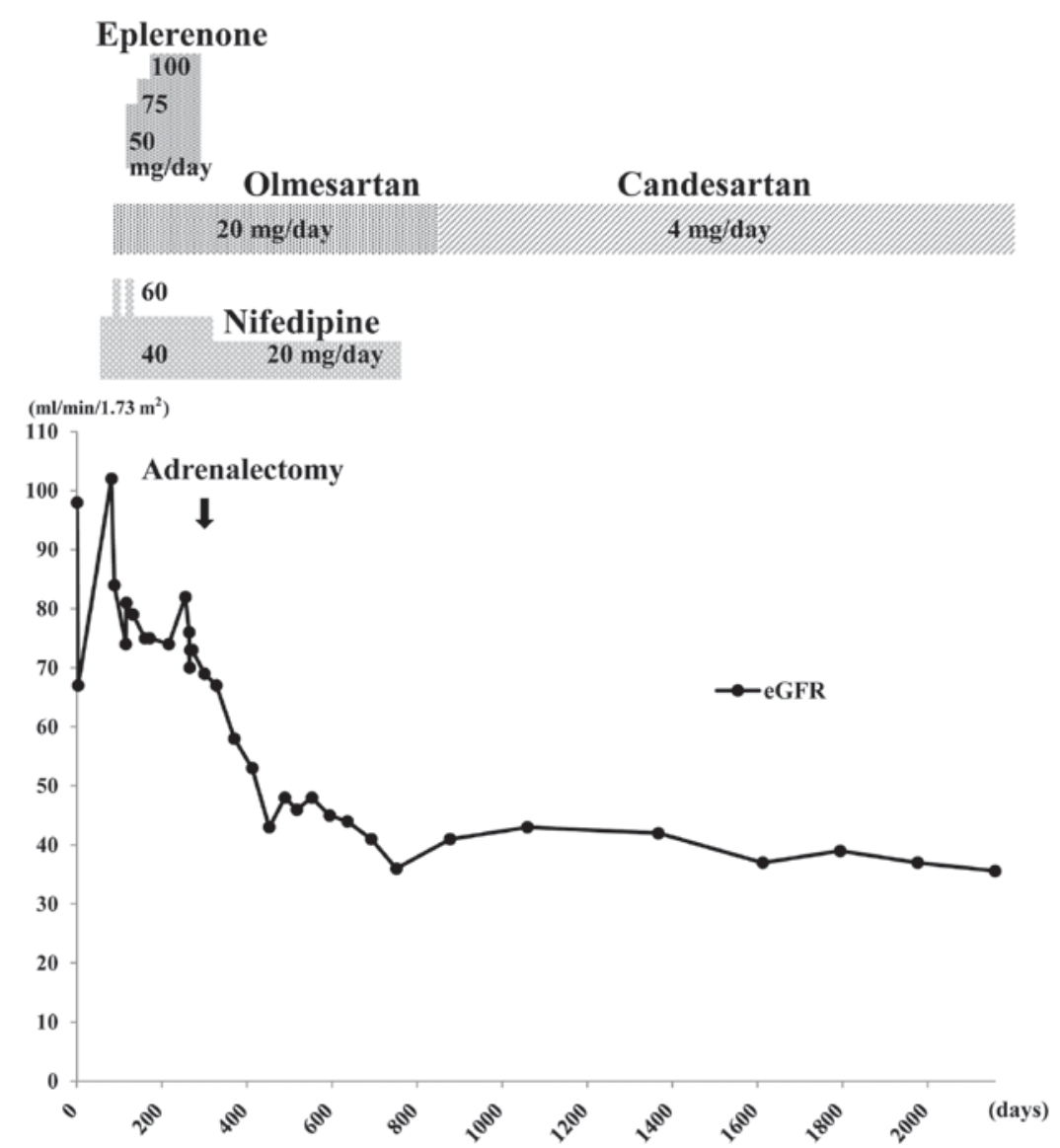

Figure 2. Clinical course. Although the estimated glomerular filtration rate declined rapidly for $\sim 7$ months after adrenalectomy, the rate of decline thereafter was much slower, consistent with the natural clinical course of autosomal dominant polycystic kidney disease.

Kao et al (7) reported that hypokalemia is an important feature that may enable the diagnosis of the co-occurrence of ADPKD and PA. In addition, a high aldosterone-renin ratio (ARR) may be a useful diagnostic tool because as in PA cases, if the only symptom is hypertension, early discovery of ADPKD and PA co-occurrence is difficult. In the present case report, hypokalemia and a high ARR were present initially $(\mathrm{K}, 2.4 \mathrm{mEq} / \mathrm{l}$; PRA, $\leq 0.1 \mathrm{ng} / \mathrm{ml} / \mathrm{h}$ and aldosterone, $149 \mathrm{pg} / \mathrm{ml}$ ), suggesting that the patient had PA.

So far, there have been 12 reported cases of combined ADPKD and PA (6,7,23-27). Adrenalectomies were performed in 8 patients $(6,7,23-26)$ and anti-aldosterone drugs were administered to the other 4 cases $(22,23,27)$. Worsening of kidney function following adrenalectomy for PA has been reported (23); the cause may be the correction of glomerular hyperfiltration once aldosterone levels have been stabilized (3-5). Therefore, overestimated kidney function due to glomerular hyperfiltration was canceled out, which led to an accurate kidney function. As a result, decline of eGFR may have occurred. Hyperaldosteronism leads to sodium and water retention, for which the kidney may compensate with hyperfiltration to excrete the excess sodium and water. Following adrenalectomy, normalization of aldosterone levels results in the return of filtration to normal levels. Kidney dysfunction 
that was previously masked by aldosterone-related hyperfiltration may then be revealed (3-5).

There is controversy regarding the length of time take for eGFR to return to normal levels following adrenalectomy. According to some reports, eGFR decreases following adrenalectomy for $\sim 1$ month, after which it stabilizes, presumably indicating underlying levels of renal function (3-5). However, other authors have reported more variable rates of decline in eGFR following adrenalectomy. Utsumi et al (3) reviewed the records of 78 Japanese patients who underwent unilateral adrenalectomy to treat PA. The eGFR decreased by 16.6-13.2 $\mathrm{ml} / \mathrm{min} / 1.73 \mathrm{~m}^{2}(16.3-13.0 \%)$ in patients with a preoperative eGFR $\geq 90 \mathrm{ml} / \mathrm{min} / 1.73 \mathrm{~m}^{2}$ $(\mathrm{n}=20)$; by $11.1-10.6 \mathrm{ml} / \mathrm{min} / 1.73 \mathrm{~m}^{2}(14.7-14.4 \%)$ in those with initial values of $60-89 \mathrm{ml} / \mathrm{min} / 1.73 \mathrm{~m}^{2}(\mathrm{n}=46)$; and by $4.8-8.7 \mathrm{ml} / \mathrm{min} / 1.73 \mathrm{~m}^{2}(10.6-18.8 \%)$ in those with a preoperative eGFR $<60 \mathrm{ml} / \mathrm{min} / 1.73 \mathrm{~m}^{2}(\mathrm{n}=12)$. These values were all measured within 1 month postoperation. The differences between pre- and postoperative values in the three groups were statistically significant (3). In the current case report, the rate and duration of the decline of eGFR following adrenalectomy likely differed from that observed in patients with PA alone. What is notable in the current case is that the kidney volume remained essentially unchanged pre- and postoperatively and blood pressure remained well controlled post-surgery. Therefore, a rapid postoperative decline in eGFR was most likely due to correction of hyperaldosteronism.

According to the Consortium for Radiologic Imaging Studies of Polycystic Kidney Disease (CRISP) dataset (www. niddkrepository.org/studies/crisp), Chapman et al (28) reported that eGFR could be calculated as follows: $(y=-0.0136$ $\mathrm{x}+112.63, \mathrm{R}=-0.37),\left(\mathrm{y}=\mathrm{eGFR}, \mathrm{ml} / \mathrm{min} / 1.73 \mathrm{~m}^{2}, \mathrm{x}=\right.$ the volume of kidney, $\mathrm{ml}$ ). If the current case is applied, the volume of each kidney was $705.4 \mathrm{ml}$ and eGFR is calculated as $103.04 \mathrm{ml} / \mathrm{min} / 1.73 \mathrm{~m}^{2}$. Therefore, the unmasked level of kidney dysfunction in the current case may be more severe at the given level of total kidney volume. The reasons for the poor kidney function of the patient cannot be determined with certainty. One potential explanation is the coexistence of progressive ADPKD masked by hyperfiltration, as well as a history of long-term hypertension. Although predicting a decrease in eGFR in patients with PA following adrenalectomy is difficult, it is a critical clinical issue. Tanase-Nakao et al (5) reported that a preoperative eGFR $\leq 76.9$ and ARR $\geq 305$ were significant predictive factors for postoperative chronic kidney disease in patients with PA. In the current case, preoperative eGFR and ARR almost fulfilled those criteria, although it is unclear if other patients similar to ours would also have similar results. Identifying similar such cases is required to clarify this issue. It was also observed that the patient's eGFR stabilized $\sim 7$ months following adrenalectomy and exhibited only a slow decline thereafter, indicating that eGFR is associated with the natural clinical course of ADPKD. Torres and Harris (29) reported that, once renal dysfunction appears in ADPKD, there is a decline in eGFR of $\sim 5 \mathrm{ml} / \mathrm{min} /$ year. Given the age of the patient, this rate of decline is not inconsistent with eGFR values immediately following postoperative decline.

The patient's blood pressure was well controlled following adrenalectomy. However, the target for blood pressure control in patients with ADPKD remains controversial.
Sarnak et al (30) reported that low targets for blood pressure slowed the progression of nondiabetic kidney disease in patients with moderately-to-severely decreased GFRs and recommended a target of $<130 / 80 \mathrm{mmHg}$ (28). In this regard, the recent HALT-PKD [Study A] (31) determined that in early ADPKD, strict blood pressure control (i.e., blood pressure $<110 / 75 \mathrm{~mm} \mathrm{Hg}$ ) was associated with better outcomes, including a slower increase in total kidney volume, decrease in left-ventricular-mass index and proteinuria, compared with standard blood pressure control, although there was no difference in the eGFR. In the current case report, proteinuria was only detected on the first visit and microalbuminuria was undetectable thereafter.

In conclusion, the current study reports the case of a patient with ADPKD whose kidney dysfunction was masked until adrenalectomy for PA caused by adrenal adenoma. This case suggests that, when patients undergo adrenalectomy to treat PA, the clinician must be vigilant for a postoperative decline in eGFR, particularly in patients with possible underlying renal disease.

\section{Acknowledgements}

The authors would like to thank Dr Osamu Suzuki for advising on pathological methods. This study was supported in part by a Grant-in-Aid for Scientific Research (C) from the Ministry of Education, Culture, Sports, Science and Technology of Japan (grant no. 16K09363) awarded to Dr Hiroaki Satoh.

\section{References}

1. Ramanathan G, Elumalai R, Periyasamy S and Lakkakula B: Role of renin-angiotensin-aldosterone system gene polymorphisms and hypertension-induced end-stage renal disease in autosomal dominant polycystic kidney disease. Iran J Kidney Dis 8: 265-277, 2014.

2. Higashihara E, Nutahara K, Kojima M, Tamakoshi A, Yoshiyuki O, Sakai $\mathrm{H}$ and Kurokawa K: Prevalence and renal prognosis of diagnosed autosomal dominant polycystic kidney disease in Japan. Nephron 80: 421-427, 1998.

3. Utsumi T, Kawamura K, Imamoto $T$, Nagano $H$, Tanaka $T$, Kamiya N, Nihei N, Naya Y, Suzuki H and Ichikawa T: Preoperative masked renal damage in Japanese patients with primary aldosteronism: Identification of predictors for chronic kidney disease manifested after adrenalectomy. Int J Urol 20: 685-691, 2013.

4. Iwakura Y, Morimoto R, Kudo M, Ono Y, Takase K, Seiji K, Arai Y, Nakamura Y, Sasano H, Ito S and Satoh F: Predictors of decreasing glomerular filtration rate and prevalence of chronic kidney disease after treatment of primary aldosteronism: Renal outcome of 213 cases. J Clin Endocrinol Metab 99: 1593-1598, 2014.

5. Tanase-Nakao K, Naruse M, Nanba K, Tsuiki M, Tagami T, Usui T, Okuno H, Shimatsu A, Hashimoto S, Katabami T, et al: Chronic kidney disease score for predicting postoperative masked renal insufficiency in patients with primary aldosteronism. Clin Endocrinol (Oxf) 81: 665-670, 2014.

6. Gejyo F, Ishida K and Arakawa M: Autosomal dominant polycystic kidney disease complicated by primary aldosteronism. Case report and review of the literature. Am J Nephrol 14: 236-268, 1994.

7. Kao CC, Wu VC, Kuo CC, Lin YH, Hu YH, Tsai YC, Wu CH and $\mathrm{Wu} \mathrm{KD}$; TAIPAI study group: Delayed diagnosis of primary aldosteronism in patients with autosomal dominant polycystic kidney diseases. J Renin Angiotensin Aldosterone Syst 14: 167-173, 2013.

8. Scheie HG: Evalution of ophthalmoscopic changes of hypertension and arteriolar sclerosis. AMA Arch Ophthalmol 49: 117-138, 1953. 
9. O'Neill WC, Robbin ML, Bae KT, Grantham JJ, Chapman AB, Guay-Woodford LM, Torres VE, King BF, Wetzel LH, Thompson PA and Miller JP: Sonographic assessment of the severity and progression of autosomal dominant polycystic kidney disease: The consortium of renal imaging studies in polycystic kidney disease (CRISP). Am J Kidney Dis 46: 1058-1064, 2005.

10. Cadnapaphornchai MA, McFann K, Strain JD, Masoumi A and Schrier RW: Prospective change in renal volume and function in children with ADPKD. Clin J Am Soc Nephrol 4: 820-829, 2009.

11. Ravine D, Gibson RN, Walker RG, Sheffield LJ, Kincaid-Smith P and Danks DM: Evaluation of ultrasonographic diagnostic criteria for autosomal dominant polycystic kidney disease 1. Lancet 343: 824-827, 1994.

12. Omura M, Sasano H, Saito J, Yamaguchi K, Kakuta Y and Nishikawa T: Clinical characteristics of aldosterone-producing microadenoma, macroadenoma, and idiopathic hyperaldosteronism in 93 patients with primary aldosteronism. Hypertens Res 29: 883-889, 2006.

13. Satoh F, Abe T, Tanemoto M, Nakamura M, Abe M, Uruno A, Morimoto R, Sato A, Takase K, Ishidoya S, et al: Localization of aldosterone-producing adrenocortical adenomas: Significance of adrenal venous sampling. Hypertens Res 30: 1083-1095, 2007.

14. Weiss LM: Comparative histologic study of 43 metastazing and nonmetastasizing adrenocortical tumors. Am J Surg Pathol 8: 163-169, 1984.

15. Weiss LM, Medeiros LJ and Vickery AL Jr: Pathologic features of prognostic significance in adrenocortical carcinoma. Am J Surg Pathol 13: 202-206, 1989

16. Matsuo S, Imai E, Horio M, Yasuda Y, Tomita K, Nitta K, Yamagata K, Tomino Y, Yokoyama $\mathrm{H}$ and Hishida A Collaborators developing the Japanese equation for estimated GFR: Revised equations for estimated GFR from serum creatinine in Japan. Am J Kidney Dis 53: 982-992, 2009.

17. Torres VE, Harris PC and Pirson Y. Autosomal dominant polycystic kidney disease. Lancet 369: 1287-1301, 2007.

18. Parfrey PS, Bear JC, Morgan J, Cramer BC, McManamon PJ, Gault MH, Churchill DN, Singh M, Hewitt R, Somlo S, et al: The diagnosis and prognosis of autosomal dominant polycystic kidney disease. N Engl J Med 323: 1085-1090, 1990.

19. Barrett BJ, Foley R, Morgan J, Hefferton D and Parfrey P: Differences in hormonal and renal vascular responses between normotensive patients with autosomal dominant polycystic kidney disease and unaffected family members. Kidney Int 46 : 1118-1123, 1994.
20. Bell PE, Hossack KF, Gabow PA, Durr JA, Johnson AM and Schrier RW: Hypertension in autosomal dominant polycystic kidney disease. Kidney Int 34: 683-690, 1988.

21. Chapman AB, Johnson A, Gabow PA and Schrier RW: The renin-angiotensin-aldosterone system and autosomal dominant polycystic kidney disease. N Engl J Med 323: 1091-1096, 1990.

22. Peixoto AJ: A young patient with a family history of hypertension. Clin J Am Soc Nephrol 9: 2164-2172, 2014.

23. Bobrie G, Sirieix ME, Day M, Landais P, Lacombe M and Grunfeld JP: Autosomal dominant polycystic kidney disease with primary hyperaldosteronism. Nephrol Dial Transplant 7: 647-650, 1992.

24. Saeki S, Ogihara T, Masugi F, Mikami H, Tabuchi Y, Seto T and Kumahara Y: A case of primary aldosteronism with polycystic kidney disease. Nihon Naika Gakkai Zasshi 75: 28-32, 1986 (In Japanese).

25. Rajasoorya, Chee TS and Ng BK: Hypertension in disguise - a trap for the unwary. Eur J Endocrinol 133: 93-66, 1995.

26. Liou HH, Tsai SC, Chen WJ, Huang TP, Huang WJ and Chen KK: The association of aldosterone-producing adrenal adenoma in a patient with autosomal dominant polycystic kidney disease. Am J Kidney Dis 23: 739-742, 1994.

27. Hoorn EJ, Hesselink DA, Kho MM, Roodnat JI, Weimar W, van Saase JL, van den Meiracker AH and Zietse R: A case of primary aldosteronism revealed after renal transplantation. Nat Rev Nephrol 7: 55-60, 2011.

28. Chapman AB, Guay-Woodford LM, Grantham JJ, Torres VE, Bae KT, Baumgarten DA, Kenney PJ, King BF Jr, Glockner JF, Wetzel LH, et al: Renal structure in early autosomal-dominant polycystic kidney disease (ADPKD): The consortium for radiologic imaging studies of polycystic kidney disease (CRISP) cohort. Kidney Int 64: 1035-1045, 2003.

29. Torres VE and Harris PC: Autosomal dominant polycystic kidney disease: The last 3 years. Kidney Int 76: 149-168, 2009.

30. Sarnak MJ, Greene T, Wang X, Beck G, Kusek JW, Collins AJ and Levey AS: The effect of a lower target blood pressure on the progression of kidney disease: Long-term follow-up of the modification of diet in renal disease study. Ann Intern Med 142: 342-351, 2005.

31. Schrier RW, Abebe KZ, Perrone RD, Torres VE, Braun WE, Steinman TI, Winklhofer FT, Brosnahan G, Czarnecki PG, Hogan MC, et al: Blood pressure in early autosomal dominant polycystic kidney disease. N Engl J Med 371: 2255-2266, 2014. 